Journal of Education and Vocational Research

Vol. 5, No. 3, pp. 138-145, September 2014 (ISSN 2221-2590)

\title{
Challenges of Using ICT in assessing and Developing Students' affective Domain in Education
}

\author{
${ }^{*}$ Ismail Abdulfatai ${ }^{1}$, Nik Ahmad Hisham Ismail ${ }^{1}$, Husein Osman Abdullahi ${ }^{2}$ \\ ${ }^{1}$ Institute of Education IIUM, Kuala Lumpur, Malaysia \\ ${ }^{2}$ Kulliyyah of ICT, IIUM, Kuala Lumpur Selangor, Malaysia \\ *abdulfunmi28@gmail.com
}

\begin{abstract}
ICT is becoming an inevitable tool in education nowadays. For any academic activities to be effective, the use of ICT is imperative. There are also a lot of benefits and improvement that ICT has brought to the field of education. These benefits and development cut across all spheres of education, such as the aspect of content, instruction and evaluation. In area of evaluation, the cognitive and psychomotor aspects of evaluation are mostly developed, based on the fact that both can be easily accessed through ICT. However, in the aspect of affective domain, the level of assessment is low and not absolutely reliable because it deals with the feelings, interest and values that learner attached to the subject matter. Hence, this study aimed at finding an effective way that ICT can be used to assess students' affective domain in the process of evaluation. In order to get in-depth understanding of the subject matter, the study employs qualitative design by using semi-structured interview to elicit information from specialists in the field of communication technology. Findings from the study indicate that the use of ICT to evaluate student affective domain requires an illustrious, diligent, and enthusiastic ICT literate teacher. Equally, there is a need to develop software that will focus more on the evaluation of students' affective domain. Meanwhile, this area that will develop students' soft skills is greatly needed to produce good citizens, employees, and government of their individual community.
\end{abstract}

Keywords: Affective, Measurement, ICT, Cognitive Domains, Assessment

\section{Introduction}

The modern trend throughout the world has brought about changes in many areas of specialization. One of the major features of these changes is the emergence of information communication technology (ICT), which has assumed great position in every field of specialization. ICT is very paramount to the extent that some disciplines cannot do without it. This is based on the premise that ICT brings about change, which is one of the necessities of every discipline. No area of specialization wishes to be backward, hence, everyone explores ICT. One of the prominent mediums through which the world will constantly experience change is technology, (Ogbomo \& Ogbomo, 2008). It should be noted that, the present world cannot survive unless with the aid of ICT. In other words, for man to survive in the modern age depends largely on access to national and worldwide information networks. ICT is the foundation for the survival and progressive change of any nation in a rapidly developing global environment. It challenges us to find a means to address a host of issues such as reliable infrastructure, skilled human resources, open government, and other essential issues of capacity building (Federal Republic of Nigeria, 2001).

Nevertheless in the field of education, there are three major areas in which students are evaluated. Bloom, Engelhart, Hill and Krathwohl (1956), divide educational objectives into three domains: cognitive, affective and psychomotor (which is sometimes described as knowing/head, feeling/heart, doings/hands) The cognitive domain is concerned with objectives involving intellectual activities ranging from remembering, applying, analyzing, synthesizing and evaluating (Fuller \& Keim, 2007). While some attributes such as attitude, motivation, and internalization of values are some of the key factors which define affective learning (Goyal \& Murthy, 2010). It is known that the only way to get feedback from student's performance is through assessment. The above mentioned three domains are peculiar in measuring educational objectives therefore; cognitive aspect can be measured through the aid of ICT, since it will measure the achievement level of the learner. However, affective domain is quite difficult to be measured through the use of ICT. There is a work on this aspect which based its research on defining the attributes of affective domain developed through an ICT- 
enriched course and characterizing the relations between them (Goyal \& Murthy, 2010). Conversely, past studies have not carry out research on how ICT can effectively measure students' affective domain. As a result, this study wishes to find out the effective way by which ICT can be used to measure the domain.

Measuring affective domain will enable educator to assess the level of learners' interest and motivation, thereby assist teacher or educator to device a method for improving students' interest and motivation. In the long run students' readiness to receive and value life-long learning shall be improved Hanus, Hamilton \& Russell (2008) and they could be able to learn independently without coercion from significant others. Equally, Popham (2011) posit that, one of the reason why affective domain is important is that, it typically influences students' behavior and promote positive attitudes towards learning as well equips students to be effective employer and employee by inculcating in them the sense of social responsibility Olatunji (2013). All these could be possible because affective learning mainly focus on students' sub-conscious mind, as result it will able to trigger student's alertness and bring fort the latent qualities of these students. It is believed that the students' affective domain deals with interest, attitudes and emotional attachment to the subject matter. One of the importance of ICT in education as mentioned in the literature is to improve student cognitive skills. However, the present information age institutions of learning have adopted the use of ICT as one of the major modes of transmission of instruction, most especially in the developed society. This means that ICT is taking the place of an instructor or teacher. With the influx of ICT in education, balance should be maintained in the way a student is being assessed through ICT. It should not focus only on the aspect of cognitive development, and partially neglecting the affective domain of students. Hence, it is very important to design an effective method of assessment in ICT that will focus on the student's affective aspect of students' behavior.

\section{Literature Review}

Introduction: In the present world, ICT and education are inseparable: It is one of the outstanding modes of instruction in education to the extent that the majority of students depend only on ICT for their degrees and knowledge acquisition. The major functions of education are to impact knowledge, teach new skills, and develop the mind, change attitudes as well as orientation. Hence, it makes individual to function effectively in the society. All the above-mentioned functions can equally be carried out through ICT. Goyal and Murthy (2010) stated information and communication technology (ICT) has become an integral part of education due to the growth and development in the field of technology, as well as the globalization in education. However, the field of education is facing some perennial challenges that range from the challenges of the content, method, and evaluation. These are the equal challenges and limitations of ICT in education. This was substantiated by (Mikre, 2011), who mentions that many people from inside and outside the education system perceived ICT as the "solution" or the most important panacea to school and educational problems and improvement. Though, many conditions can be considered as limitations of ICT use in education, one of the greatest challenges is in the area of educational assessment. One major example is the absence of user-friendly methods in analyzing test results at the school level (Martin, 2004). Nevertheless, the most challenging area from all the assessment domains is the aspect of affective domain. A greater part of the educational process focuses mainly on the development of cognitive as well as the psychomotor domain. The development of affective domain remains mostly unattended to (Adkins and Caldwell, 2004). Therefore, this section of the paper wishes to deal with the stages involve in the affective domain in education as proposed by Bloom et al (1956), and how it relates to ICT in education.

ICT and education assessment: Education is the major source of development throughout the world. It encompasses the whole aspect of human life. It brings about changes and development in any civilization. Equally, education is the mother of all inventions. It gives birth to all civilizations around the world. Thus, ICT is the product of age long search of knowledge Education gives birth to ICT. Today the use of ICT has pervaded the realm of education. According to Mikre (2011), it's making constant changes in society, and affecting all aspects of life. The influences are felt greatly in schools. ICT provides both learners and teachers with more opportunities in adapting learning and teaching to individual needs. Therefore, society is aptly forcing schools to respond to this technical innovation. In fact, in this modern age, education may not be effective without the use of ICT, due to its importance in the field of education. ICT is one of the main skills needed to access and enrich learning of all kinds. It is all about communication, as well as the world in which our children are growing up. It is crucial that whatever they do; they will have to be ICT-literate. It connects all areas within the 
curriculum. The Internet can be a powerful resource; if children are not connected at home school provision becomes even more important, (Naace, 2012). Equally, Grace, Jeremy, and Charles (2003) also commented on the importance of ICT in education, as means to develop students not just in terms of their achievement but also their ability to interact in today's society. Education, in recent years, has invested a great deal in ICT systems to strengthen not only its administrative function but also to develop learning and have a positive impact on results. The above statements show that the use of ICT in educational setting is unavoidable. Since ICT is one of the inevitable factors in education, it means that whatever is seen as the problem of education should be taken seriously by educators. Meanwhile, one of the major problems of education after the issue of contents as well as methodology is the educational assessment. Invariably ICT is also used as a tool for educational assessment. The Namibia Training Authority (2006), states the use of ICT in education assessment thus; ICT enhances a range of effective assessment and evaluation methods. Teachers use ICT to:

- Assess and evaluate learner attainment of relevant curriculum outcomes

- Recording learners' performance results

- Analyze and interpret learners recorded performance results

- Outline communication procedures to communicate learners' performance results to stakeholders

- Modify teaching strategies and resources based on learners' performance

In academic assessment, students are evaluated on three aspects. Bloom et al. (1956), divides educational objectives into three "domains": cognitive, affective and psychomotor domains. Nevertheless, students are assessed on their knowledge and cognitive skills but rarely measure the attitudes that will lead to the appropriate practices of what they have been taught within the classroom at the workplace (Fuller \& Keim, 2007). Only a few studies have been carried out on the affective aspect of assessment, based in the fact that it depends on the subjective disposition of a learner.

ICT and affective level of assessment: The above discussion indicates that there are some levels of relationship between students' affective domain and ICT use in education, in view of the fact that, affective domain deals with objectives involving emotions or a degree of acceptance or rejection, which may be expressed as interests, attitudes and values (Fuller \& Keim, 2007). In education, this concept which is expressed as a single concept has been categorized by some educators. For instance, Krathwohl, Bloom and Masia (1964) proposed five-level taxonomy of the affective domain as follows:

- Receiving: The learner is feeling and sensing the usefulness of the topic and is willing to learn about it.

- Responding: This is characterized with some level of acceptance from the learner who ranges from reluctant compliance, via willing response, to a sense of satisfaction in doing what is required.

- Valuing: The learner attaches worth to the topic, believes in it and is committed to it.

- Organization: The learner organizes a set of values into a value system that can be used to respond to situations.

- Characterization by a value or value complex: At this stage the learner has completely internalized the values, at the point to which they form part of the personality characteristics of the individual.

All these categories of affective evaluation required to be assessed through ICT. However, studies have been done on the aspects that are related to it. Fuller and Keim (2007), for example carried out a study on the assessment of attitudes as well as cognitive achievements through ICT. Meanwhile, a study has also been done to determine the components of students' affective domain developed in an ICT-enriched course (Goyal \& Murthy, 2010). However, this study is interested in looking at how ICT can be used to assess student's affective domain effectively and thereby bring about development in student's disposition towards learning.

\section{Methodology}

This study employs a qualitative method, under which action research design is adopted. This is due to the fact that action research has an applied focus (Creswell, 2005). The rationale behind using this design lies in the premise that the present study wishes to highlight methods that could be used to improve the use of ICT 
for students' affective domain in the field of education. Equally important is that, the aim for the study is to inform and improve practices within the field of education (Mills, 2000). This form of research is especially effective in obtaining information about and subsequently improves, the methods, used in an education setting (Mills). Action design is used when there is a specific educational problem to solve (Watters, Christensen, Arcodia, Ryan, \& Weeks, 1998). However, in order to have an in-depth understanding and come up with a profound outcome, the researchers employed a qualitative approach by using an interview as the instrument for data collection to this study.

Participants: The present exploratory study analyzed the contributions 3 ICT specialists from the Faculty of Information Communication Technology, in International Islamic University Malaysia. The first respondent is a lecturer, an associate professor from the faculty, who has more than 15 years experience in teaching. The second participant is part-time lecturer, a $\mathrm{PhD}$. student with more than 10 years experience at both secondary and tertiary levels of education, who is also from the same faculty. The last participant is also a first-year PhD. student in the Faculty of Information Communication Technology. The respondents were chosen because of their level of experience in the field of education as well as their wealth of knowledge in ICT, and those criteria ensure the credibility of the study.

Establishment of Credibility and Trustworthiness of the Instrument: The establishment of credibility and trustworthiness were carried out through the interview questions designed. The necessary research modifications were made by a Professor in the Department of Educational Psychology of the International Islamic University Malaysia. In addition, the checking of interview protocol was done by an expert at the Institute of Education, International Islamic University Malaysia before the actual research was conducted. The pilot interview was carried out to test the validity of the interview questions; hence necessary modifications were subsequently made on each item that the participants were expected to respond to.

Data Collection: Semi-structured interviews were conducted with the aim of gaining insight into and unraveling answers from the questions which the research raised. The questions were drafted and were sent to the proposed respondents prior to the given dates of the interview for input to be added. Data was collected through an interview, whereby some practitioners as well as ICT specialists were interviewed. The conversation from the interviews was recorded with the permission of the participant being interviewed using a MP3 recorder that was later listened to repeatedly, transcribed and read as well, to obtain an overall understanding of the respondents' view. Lodge, cited in Gorman and Clayton (2005), states that, the aim of an interview is to identify with the subjects, to experience the milieu as they experience it. Thus data collection was achieved through the staging of the interview, using the available archives and publications as well as searching the websites thoroughly.

\section{Data Analysis}

Data analysis is the process of bringing order, structure and meaning to the mass of collected data (RiceLively, 2004). Therefore, all the interview transcripts were read by the researchers and coded in the style of a grounded theory approach where analysis is done base on inductive stance, and the investigator strives to derive meaning from the data (Merriam, 2009). This involves coding, content analysis or ethnographic analysis following a nonlinear process. Though it may look messy, ambiguous and time consuming, it is indeed a creative and fascinating process. The themes in these particular interviews were extracted and analyzed according to the research questions and issues identifiable with the literature as well as on the field revelations (thereby inculcating the participants' view). Four category headings were generated from the data and under these all of the data were accounted for. Two independent researchers were asked to verify the accuracy of the category system and after a discussion with them; minor modifications were made.

Discussion: The nature of the study warranted the use of a qualitative approach, in which interviews were conducted in order to gain in-depth knowledge on the subject matter. The interviews were conducted by the researchers with specialists from the field of ICT, majorly university lecturers and PhD students. From the interviews, themes were coined out, that represented the statement of the interviewees emerged. The themes could, by careful analysis, be likened to the coding of the qualitative data; a process described by Saldana $(2009$; p. 3 ) as "...summative, salient, essence-capturing..." of data collected from interviews, 
participant's observation field notes, artifacts, etc. In this study the themes were outlined in heading and subheading form in order to foster proper discussion and analyses. The themes generated from the interviews are as follows.

- On-line Evaluation Program

- Creation of software that monitors response progress of learners.

- Learners should be evaluated through on-line repository.

- Benefits of students' affective domain assessment through ICT

On-line Evaluation program: In measuring students' level of reception, one of the respondents proposed that, on-line evaluation program should be created by the instructor, such as on-line active learner or MyCourse. Students will respond to this and the instructor can measure the level of reception of the individual student. He stated thus in his explanation;

Basically, online we have enough evaluation sites, especially from.

Publisher, we have Parona, they call it active learning.

The above statement was supported by a study conducted by the International Society for Technology in Education, (ISTE, 2011) that teachers apply technology in evaluating student learning of subject matter using a variety of assessment techniques. This involves the development of software artifacts, be it Java programs, a complex spreadsheet or a set of word processing style sheets and macros, to assess student,( Fuller and Keim, 2008). However, all these require the effort of the instructor because one should bear in mind that, ICT on its own cannot perform the assessment roll. Everything depends on whatever we program to it. Equally, important is the fact that the feedback is also monitored by the instructor. Technology is never a replacement for pleasant teaching. Without skilled instructors, no electronic delivery can achieve good results. Nevertheless, neither can traditional classroom teaching, (Cairncross \& Poysti 2003). Hence, instructors should make a complimentary effort with the usage of ICT in assessing students and constructing all necessary apparatuses available to render the evaluative program effective.

Creation of software that monitors response progress and interest in the learner: The question that was under this heading is: How can ICT evaluate the level of student's response and interest towards an instruction? In the conventional class, an instructor monitors the level of students' response through observation. It should be noted that, the level of attention given for an object depends upon the level of interest one has towards it. Therefore, in the case of ICT, what will it use to evaluate the student's response? One of the respondents states the following.

We have to be creative in developing application that attracts student's Interest. Every student is different. Some student loves IT while others prefer class environment. You don't have one solution for the entire problem.

Monitoring learners' progress is an important issue in education. That is why Halverson and Shapiro (2012) state that, In order to provide quality education; planners and leaders should create and store data document progress toward educational outcomes. However, in this context the respondent is advocating for the creation of software that could monitor students' response and interest progress. This will enhance early detection of problem militating against students' interest and response; thereby provide an avenue to develop students' interest level.

Learners should be evaluated through an on-line repository: The question that was asked on this aspect was "How is it possible to assess the way a learner organizes a set of values derived from instruction?" In other words, it should be noted that, an instructor inculcates a set of values in the learner, most especially in the area of humanity. The question is then addressing how the set of values could be evaluated through the use of ICT? On this issue, one of the interviewees asserts that there are so many repositories that are available now, even to the level of research students. There is a research monitor system on-line that give them, research updates, programs and so on. On-line, instead of usual manual process level, in essence, it is very important because it reduces the time and is more efficient and has many other advantages.

Benefits of students' affective domain assessment through ICT: The benefits highlighted from the interview are as follows. 
- ICT use in assessment ensures student privacy: this is beneficial because, individual student interacts with his or her laptop and responds to any question posed by the instructor. Such a student is not under pressure of crowd, and the response is just between the student and the instructor. Such student will feel free to divulge information as it will be useful for both student and the instructor to make their generalization.

- Easy for both students and instructor: this aspect is advantageous based on the premise that student responds to instruction or information at anytime within the frame of time agreed upon by both student and instructor. It can also be done at anywhere in the world in as much, there is availability of the Internet.

- Instructor receives detailed information: due to the availability of time and due to privacy, student may provide detailed information about the subject matter.

All these benefits are explained in the statement of one of the respondents that goes as follows: Actually, it makes simpler and faster, even pointed that essay questions are marked, programming questions are marked. This is easier for lecturer and for student net and their own cases, because you are going to create problems student by student cases, if a student is a slow learner, you give easy question, do not give harder one, vice versa to a faster learner this thing can make students label, example, previously when I am teaching FQA, students complain that they do not have been non private, they introduce to pop up quiz in URL because of that now when they come to class and when they read, based on that quiz, they know their expectation, type of question.

In short, the use of ICT in the affective aspect of education is not something ordinary. It requires personnel that are dedicated, insightful and creative in the field of education.

Findings: From the conducted interviews conducted and the literature, the following are findings regarding the use of ICT in evaluating students' affective domains.

- The effective use of ICT in education requires personnel that are well versed in both the fields of education and information technology.

- In order to create software that will develop students' interest, various students' needs should be studied as well as their values. Software that will cater for all these will then be developed.

- Full ICT course, such as web designing, creating blogs and others is needed to be made as one of the core courses within the field of education.

- It is also noted from the discussion that it is very important for all students to be ICT literate, so that most students can keep up with the current trend in the world, thereby meeting the current challenges.

- Lastly, it could also be discerned from the discussion that soft skill is developed through the affective domain, and the world now is in technology era where many things depend on technology to be effective. Hence, there is a need to create different software that will cater for the development of human affective domain.

The major implication of the above finding to the field of education is that, it has made it imperative that knowledge of ICT should be one of the core courses for teacher education as well as becoming a requirement for teachers' employment at all level of education. Due to this, students and teachers, most especially from developing countries could be abreast and aware of the modern trend in the world. In consonance to this, the Assistant General for education proclaimed that the system of education is going through a constant pressure to use new ICT to teach student the knowledge they need in the $21^{\text {st }}$ century. Therefore creating and implementing effective ICT enabled teacher education programs is the key to fundamental wide range education reforms UNESCO (2002). Equally, more emphasis should be laid on inculcating soft skills in the students through ICT assisted programs due to the constant change and development in technology, so that students could be prevented from being mechanical in handling issue and lacking worthwhile skills and ethics for moral development and civil responsibilities. 


\section{Conclusion}

This study deals with the issue of assessment in education, which covers the aspect of affective domain and focuses upon the issue of students' interest, value and disposition towards learning. The study reveals that using ICT in the area of assessment of learners' affective domains requires a very zealous, efficacious and ICT literate teacher to make it effective. As a result, effort should be made to train teachers in the field of ICT. Based on this fact the study suggests that ICT should be made one of the core courses in teacher education. Furthermore, students' interest and values attached to their studies should also be considered in creating more software which will be able to cater for their needs in these respects. It should also be noted that the influx of ICT in education is at its climax hence, efforts should be made to cater for all areas of education, including the aspects of students' affective domains so that, the aspect students' soft skills shall be developed, which will later be useful for them, as good citizens, and good government in their country.

\section{Reference}

Adkins, B. \& Caldwell, D. (2004) Firm or subgroup culture: where does fitting in matter most? Journal Organizational Behaviour, 25, 969-978.

Bloom, B. S., Engelhart, M. D., Furst, E. J., Hill, W. H. \& Krathwohl, D. R. (1956). Taxonomy of Educational objectives: the classification of educational goals; Handbook I: Cognitive Domain New York, Longmans, Green, 1956.

Cairncross, F. \& Pöysti, K. (2003). ICTs for education and building human capital. International Telecom Union. Available at http://www.itu.int/osg/spu/visions/

Creswell, J. W. (2005). Educational research: Planning, conducting, and evaluating quantitative and qualitative research $\left(3^{\text {rd }}\right.$ edn $)$.

Fuller, U. \& Keim, B. (2007). Should we assess our students' attitudes? In Proc. Seventh Baltic Sea Conference on Computing Education Research (Koli Calling 2007), Koli National Park, Finland. CRPIT, 88. Lister, R. and Simon, Eds. ACS. 187-190.

Gorman, G. E. \& Clayton, P. (2005). Qualitative research for the information professional A practical handbook Facet Publishing, 7 Ridgmount Street London WC1E 7AE.

Goyal, M. \& Murthy, S. (2010). Probing students' affective domain in an ict-enriched course. Institute of Technology Bombay Mumbai India.

Grace, J. \& Charles, K. (2003). A short review of information and communication technology and basic education in LDCs - what is useful, what is sustainable? International Journal of Educational Development, 23, 627-636.

Halverson, R. \& Shapiro, R. B. (2012)._Technologies for Education and Technologies for Learners: How Information Technologies are (and Should Be) Changing Schools. Wisconsin Center for Educational Research (WCER), Working Paper 2012-6.

Hanus, J., Hamilton, S. \& Russel, J. S. (2008). The Cognitive and Affective Domain in Assessing the Life-Long Learning Objective United State Military Academy America society for Engineering Education

Krathwohl, D. R., Bloom, B. S. \& Masia, B. B. (1964). Taxonomy of Educational Objectives: The Classification of Educational Goals. Handbook 11: Affective Domain David Mckay Company Inc.

Martin, C. (2004). ICT in Education: Possibilities and Challenges. UOC www.UOC.edu

Merriam, S. B. (2009). Qualitative Research: A Guide to Design and Implementation. Jossey-Bass A Wiley Imprint 989 Market Street, San Francisco, U. S. A.

Mikre, F. (2011). The Roles of Information Communication Technologies in Education. Ethiopian Journal of Education and Science, 6(2), 1998-8909.

Mills, G. E. (2000). Action Research: A guide for the teacher researcher. Upper Saddle River, N. J: Merrill/Prentice Hall

Naace Magazine. (2012). ICT in Education is important! Naace PO Box 611 Nottingham NG 118TN http://www.naace.co.uk/Privacy.

Namibia Training Authority. (2006). ICT Skills for Educators A SSESS AND E VALUATE.

Olatunji, M. O. (2013) Teaching and Assessing of Affective Characteristics: A Critical Missing Link in Online Education. International journal on New Trends in Education and their Implication, 4(1), 1309-6249 
Ogbomo M. A. \& Ogbomo E. F. (2008). Importance of Information and Communication Technologies (ICTs) in Making a Healthy Information Society: A Case Study of Ethiopia East Local Government Area of Delta State, Nigeria Library Philosophy and Practice, Delta State Abraka Nigeria.

Popham, W. J. (2011). Transformative Assessment in Action: An Inside Look at Applying the Process. ASCD 1703 N. Beauregard St. Alexandria, VA 22311-1714 USA.

Rice-Lively, M. L. (2004). A Qualitative Research for Information Professional: A practical Hand book by G. E. Gorman Book.

Saldana, J. (2009). The Coding Manual for Qualitative Research, Sage Publication London. Trucano, Michael. (200). Knowledge Maps: ICTs in Education. Washington, DC: info. Dev / World Bank.

UNESCO. (2002). Information and Communication Technologies in teacher Education: A planning Guide> Division of Higher Education, 7, Place De Fontenoy, 75352 Paris 07 SP France.

Watters, J. J., Christensen, C., Arcodia, C., Ryan, Y. \& Weeks, S. (1998). Action Research in Practice: Partnership for Social Justice in Education. (pp. 250-279) London and New Routledge. 